\title{
Exploring Challenges Faced by Students as they Transition to Social Justice Work in the "Real World": Implications for Social Work
}

\author{
Katie Richards-Schuster \\ Mary C. Ruffolo \\ Kerri Leyda Nicoll \\ Catherine Distelrath \\ Joseph Galura \\ Alice Mishkin
}

\begin{abstract}
For students who are actively engaged in social justice efforts on their college/university campuses, the transition from a relatively easy platform for engagement to the "real world" can pose significant challenges and create new realities for negotiation. Little is known, however, about the nature of these transitions into post-graduate social justice experiences. Drawing on an open-ended survey of recent graduates (92 respondents, $50 \%$ response rate) from a social justice minor in a school of social work, we explore the ways in which respondents described their transitions into social justice work, focusing on a set of key challenges that emerged from our analysis and reflecting on the implications of these challenges for social work practice and future research. Understanding some of the challenges in making this transition will help social work and non-profit administrators to better support this population's future volunteer, service, and employment needs.
\end{abstract}

Keywords: Social justice, higher education administration, social work, community organization, social action

While social work has a particular and unique commitment to educating students with a social justice orientation, the field is not alone in producing such students, as more and more colleges and universities establish active social-justice- and community-oriented majors and minors apart from BSW and MSW programs (Glass, 2013; Harkavy, 2006; Hoy, Johnson, \& Hackett, 2012). In keeping with this trend, many social work schools have engaged in curricular innovations that promote engaged learning and active involvement in communities (Burke, 2011; Glass, 2012; Rome \& Hoechstetter, 2010). Some schools of social work are developing social work minors or related social justice minors as an alternative to the BSW program. Although only a few social work schools offer undergraduate non-BSW programs, these innovations offer the potential for a social work footprint on undergraduate campuses and create the possibility of pipelines from undergraduate to master's or doctoral level education in social work (Richards-Schuster, Ruffolo, \& Nicoll, 2015).

For highly motivated students who are actively engaged in these minors, majors, and other social justice efforts, the transition from a relatively easy platform for engagement to the "real world" can challenge individuals' understanding of social justice and their own identities as social change agents and can create new realities for negotiation. The reality

Katie Richards-Schuster, AM, PhD is an Assistant Professor in the School of Social Work at the University of Michigan. Mary C. Ruffolo, LMSW, PhD is a Professor in the School of Social Work at the University of Michigan. Kerri Leyda Nicoll, MDiv, MSW, PhD, is an Assistant Professor of Social Work in the Department of Sociology, Anthropology \& Social Work at the Massachusetts College of Liberal Arts in North Adams, MA. Catherine Distelrath, MSW, is a Research Assistant in the School of Social Work at the University of Michigan. Joseph Galura, LMSW is a Lecturer and Advisor in the School of Social Work at the University of Michigan, Alice Mishin, LLMSW, is a Lecturer and Program Manager in the School of Social Work at the University of Michigan. 
of these transitions - and the challenges that emerge - have implications for the social work and non-profit settings that become the first employers for many of these students. Yet little is known about these transitions and the immediate issues - both positive and negative - that students face as they enter this new realm of engagement.

In this article, we offer a first step toward such understanding by examining the immediate issues and challenges that new graduates have faced in staying involved in social justice work and service in the first three years after graduating from a social justiceoriented minor. Drawing on an open-ended survey of new graduates who had recently completed a social justice-focused minor within a school of social work, we explore the ways in which respondents described their transitions into the "real world." We examine trends in their descriptions, focusing on a set of key challenges that emerged from our analysis and reflecting on the implications of these challenges for non-profit settings, social work education and practice, and future research.

\section{Background Literature}

Over the last several years, higher education in the United States has experienced an increased sense of responsibility for educating young adults not just academically, but civically as well (Bringle, Clayton, Steinberg, \& Studer, 2011). As students have expressed a desire to perform more community work and become more engaged in social justice activities both on and off campus, institutes of higher education have begun working to fulfill that desire, offering an increasing number of service learning courses, civic engagement minors and majors, and co-curricular service and civic engagement activities (Bringle et al., 2011; Colby, Ehrlich, Beaumont, \& Stephens, 2003; Steinberg, Hatcher, \& Bringle, 2011). As these programs grow and expand, there is a strong desire by social work and other allied fields to support students as they transition out of the college/university environment and adapt to the various ways that social justice activism takes shape in their lives (Flanagan \& Levine, 2010; Wendlandt \& Rochlen, 2008).

Little is known, however, about how these undergraduate initiatives impact students as they transition from higher education to work in the "real world." This is especially true for the millennial generation, which is the primary cohort of students in many of today's undergraduate colleges and universities, including our own. Recent research demonstrates an overall optimism among young adults about their lives and the world in general that is somewhat unique to the millennial generation (Murphy, Blustein, Bohlig, \& Platt, 2010). Researchers have described this as a tendency to possess "world-conquering ambition" and a much greater emphasis than previous generations on personal identity and civic engagement in the workplace (Alsop, 2008; Arnett, 2004; Murphy et al., 2010). This ambitious, civic-minded outlook often leads to disappointment, however, when these young adults transition to their first jobs, finding themselves in mundane positions and wondering whether they are actually contributing anything to their organizations or, more importantly for them, to society (Alsop, 2008; Arnett, 2004; Murphy et al., 2010).

Many students entering college today have a richer background in civic engagement and social justice than ever before, primarily in the area of volunteering. Among other things, they bring to campus a variety of experiences with community-based work, along 
with a disposition of unfailing confidence in their abilities. It then becomes the role of colleges and universities to foster the identities that have been formed through adolescence and continue to challenge the depth of civic engagement within each student. This is being done, more and more, through an intersection of education- and community-based programs (Bringle et al., 2011; Colby et al., 2003; Steinberg et al., 2011).

Murphy et al. (2010) found that, regardless of their feelings about the ease of their transition during the gap years, many young adults share a common sense of the value of community and social support in their lives. After leaving the comfort of the college community, many students elicit support and encouragement from their family and friends that keeps them motivated through their transition. This sense of value placed on community support likely develops most for students during their college years, particularly if they have spent time learning through community-based programs and instruction. There is limited research, however, that focuses specifically on the postgraduate outcomes of those who participate in service- and community-based programs, and very little attention is given to how these programs impact this growing population of alums in different and presumably heightened ways compared to other graduates (Keen \& Hall, 2008).

While attention to alumni transitions and the particular challenges faced by this generation of social justice-minded young adults is growing (Polach, 2004; Roksa \& Arum, 2012), little research has focused on the nature of immediate (first, second, or third year post-graduation) transitions from undergraduate to alumni status for social work and other social justice-oriented students. Mitchell, Battistoni, Keene, and Reiff (2013), for example, discuss the importance of building an "enhanced civic identity" that sustains the transition from undergraduate to alumni, outlining fundamental skills such as collaboration, voice, reflective practice, and engaged scholarship. These skills are developed during college and become necessary for civic leadership over time, but the majority of studies have focused on alumni five or more years after graduation. Other studies finding significant correlations between collegiate engagement and post-college civic involvement have also used longer time frames (Besser, 2012; Bringle et al., 2011; Goldsberry, 2007).

Knowledge about the specific challenges facing students in the initial post-graduation years could prove to be particularly important given the fact that these years are often indicative of long-term trajectories (Roksa \& Arum, 2012). While it is true that many college graduates face a transition shock, we are particularly interested in those students embarking on social justice careers because of the potential impact on their long-term engagement in social work-related fields. If schools of social work - whether they offer BSW programs or social justice minors - are to continue to build a robust cohort of lifelong social justice practitioners, we must advance discussions about how best to support our graduates in making successful post-graduate transitions. This paper contributes to such discussions by examining the immediate issues and challenges that students encounter as they leave social work and social justice-oriented programs and the implications of those challenges for education, research, and practice in social work and allied fields. 


\section{Methods}

In fall 2013, our team of researchers conducted a pilot survey of alumni from an interdisciplinary social justice-focused minor program offered by a school of social work. Until 2010, this school of social work, housed in a large public university, provided graduate education for more than $600 \mathrm{MSW}$ and $\mathrm{PhD}$ students each year but had no undergraduate programs. The minor discussed in this paper, which began in 2010, is the first and only undergraduate program that the school of social work offers and was created as a multidisciplinary program aimed to support students interested in social justice, community action, and social change (see Richards-Schuster et al., 2015; RichardsSchuster et al., 2014, for more details about the minor's development and curriculum). There is no BSW or social work major program offered at this university.

The goals of the minor, which is explicitly not intended to be a BSW program, are to enable students to: (a) examine community action and social change concepts using a multidisciplinary framework, (b) address community action and social change efforts in multilingual and multicultural communities, (c) integrate social justice values into the community action and social change processes, and (d) engage in service learning opportunities to promote community change initiatives.

The courses included in the 16-credit minor are intended to provide students with theoretical frameworks for understanding social change, skills for self-identity development and facilitation in diverse settings, experiences in service-learning or community-engagement courses, practical skills for community change work, and opportunities for integrative reflection. In addition, the minor offers co-curricular activities to complement course-based learning. These include social justice fairs, speakers and panels, community-based experiences, community-building activities, and opportunities to hear about and learn from the experiences of program alumni. Drawing on systems and community action frameworks, the many components of the minor were designed to prepare students to engage in social justice/change work throughout their lives, whether they pursue traditional social work careers or enter fields as diverse as sports management, biomechanics, or music.

\section{Research Design}

Our pilot survey of the alumni of the minor was initially designed to gather information about the experiences of alums post-graduation, both in order to help in developing better supports for future cohorts as they transitioned to the "real world" and to assess the implications of these experiences for social work and social justice education more broadly. Our specific questions were: (1) What are the challenges that highly motivated, socialjustice-focused students face as they graduate from college and enter the "real world"? (2) What are the perceptions of these new graduates as they move into social work and related non-profit settings?

To gather this information we created an online, open-ended survey. In the survey, we asked alumni to share about their post-undergraduate work (paid, unpaid, continuing education), discuss accomplishments they had achieved since graduating from the minor, identify challenges they had faced, and reflect on what they had learned (and not learned) 
from the minor (e.g., what has been useful, what has mattered most to them in their postgraduation work, what they wish they had learned, and what advice they would give to current students). Because this was a pilot survey and we were looking to generate themes rather than test particular hypotheses, we intentionally kept the survey open-ended (Creswell, 2014).

Using Qualtrics, an online survey tool, we administered the survey to alumni from the first three cohorts of the minor from 2011 to 2013 (n=187). We reached out to alumni using email addresses that they had provided at graduation or updated contact information they had sent of their own accord. After sending three follow-up emails as reminders to encourage alumni to complete the survey, our final response rate was approximately $50 \%$ $(n=92)$. Alumni from each of the three classes provided answers.

The sample of survey respondents consisted of 71 women and 21 men. Of the 92 respondents, 75\% identified as white, 6.5\% identified as Black, 6.5\% identified as Hispanic, $5.5 \%$ identified as Asian or Pacific Islander, and 6.5\% chose not to respond. Although over half (56.5\%) of the respondents had been social science majors, respondents also reported a variety of undergraduate majors, including art and design, science, business, and cultural studies. The overwhelming majority of the students in this sample completed college within four years and were in their early 20s at the time of graduation. At the time of response, participants were in a range of post-college opportunities, most of which were in the nonprofit or public sectors, social work, or social justice fields (see Table 1).

\begin{tabular}{lc}
\hline \multicolumn{2}{c}{ Table 1. Post-Graduate Involvement of Study Participants ( $n=92)$} \\
\hline Post-Graduation Involvement & \# of Alums \\
Extended service program (AmeriCorps, Teach for America, Peace Corps, etc.) & $23(25 \%)$ \\
MSW or Joint Master's Program & $22(24 \%)$ \\
Non-profit or government employment & $23(25 \%)$ \\
Other post-bacc. degree at U of M or other school & $14(15 \%)$ \\
For-profit or freelance work & $3(3 \%)$ \\
Unemployed/ No response & $7(8 \%)$ \\
\hline
\end{tabular}

\section{Analysis}

As our survey questions were largely open-ended and we were interested in exploring responses without particular predefined hypotheses, we approached our data using thematic analysis (Boyatzis, 1998; Creswell, 2014; Denzin \& Lincoln, 2011). Multiple research team members reviewed the survey responses, resulting in the identification of several potential thematic codes. Once these codes had been identified, the data was reviewed again in an effort to locate all instances of the identified themes/codes in each individual's survey responses. The reviewers then compared their codes and sorted them into three major categories: (a) current experiences, (b) challenges, and (c) the translation of learning from the university to the "real world." Using these categories, the data was reviewed yet again to uncover related sub-themes and ensure conceptual saturation (Corbin \& Strauss, 2008; Glaser \& Strauss, 1967).

The team also used QSR International's NVIVO 10 software, a qualitative data analysis program that assists with pattern-based coding and theme tracking, to explore 
word frequencies and response trends (QSR International, 2012). In this article, we focus specifically on the themes that emerged related to challenges graduates faced as they transitioned from undergraduate education to post-graduate experiences.

\section{Emergent Themes: Critical Challenges in Transitions}

While there were many successes that graduates faced during their transitions from undergraduate education to post-graduate life and work, these successes were most often accompanied by challenges. Approximately two-thirds of our respondents noted specific challenges they had faced during their post-graduation transition. The remaining third did not explicitly acknowledge challenges, which could mean that they transitioned without challenges or that they failed to mention them in their survey responses. We acknowledge that transitions are complex and involve both ups and downs, but we chose to pay particular attention to challenges in this paper in order to highlight the ways in which schools of social work might more fully support social justice-focused graduates.

\section{Challenges with Adjustment to New Communities}

More than a third of the students who responded to this survey described challenges related to their adjustment to new community environments. This is not terribly surprising, as one would expect that students who have spent years in one location might have difficulty relocating and starting anew outside of their familiar surroundings. Building relationships, learning new jobs, and negotiating the requirements of living in new cities are challenges likely faced by many recent college graduates. For many, this was their first experience in moving to a new community without the structures and supports of a university environment, and for those beginning social-justice-focused positions, it often entails adjustments not only to new locations but also to the economic and social realities facing the communities they are entering and with whom they hope to work.

As one respondent in his first year post-graduation reported:

My biggest challenge by far has been adjusting to my community outside of work. It is a low-income Black community centered around the church in a town ravaged by the collapse of industry. I can relate in some ways, but I'm not religious at all and it's not a great place for 20-somethings. That being said, I feel it's important to be involved in the community as much as you can, so it has been tricky to navigate being present with practicing self-care and not compromising myself.

For this respondent, moving to a new community was challenging, not only because he did not know people and did not feel like he fit in with the culture around him but also because he wanted to become a part of this community, sharing in its struggles and accomplishments, while still maintaining his own identity. He was deeply committed to living in this community, not just physically but also socially, wanting to build relationships with his neighbors and other community members, but adjusting to life there was still a challenge. "I' $m$ not sure (the minor) really prepares you for the full experience," he said, "since it's gonna be different no matter who you are, but it does emphasize the importance of knowing your community and I realize now how important that is to take that to heart." 
Other respondents made similar comments about the challenges to adjusting to new communities and new environments:

There have been a lot of challenges, from moving away from everything I've known, to adjusting to a new culture, language, and career...I am constantly reflecting on my role and what I hope to accomplish here.

It has been overall a challenge to move to a new city and a new community to work in the social work field...It is a challenge to network and start 'fresh' when you are young and continuing to move to new environments.

\section{Frustration with “Social Justice” Ideology}

Another theme that emerged was the challenge of ideological frustration around what social justice looked like in reality. Despite feeling that their experiences in college and in the minor had given them the skills to engage with others and to work collaboratively, many of our respondents still expressed a stark realization that, as one student put it, "no one wants to talk about social identities and social justice as much as college students do.”

In some ways the respondents described the difference between the theoretical frameworks around social justice and the practical implications of working for change on the ground, especially as it related to awareness around social identity. Despite having taken service learning courses or participated in internships, students expressed feeling unprepared for moving into organizational environments that differed from their experiences surrounded by other social-justice-minded students in college.

It has been very difficult working with (an) organization as a whole who, at times, do not carry the same sort of communal and cultural values as (the minor)...I am feeling a bit frustrated by all of this, to be honest.

Some of my biggest challenges are working with people who have been in the criminal justice/juvenile justice field for years. They seem to be more skeptical and pessimistic. They also doubt me because of my identity as a young white woman who is passionate about challenging our prison system.

Working with people who do not share my interest/passion/knowledge around social justice and community work has been a challenge.

Even among others who seemed to care about similar issues and share a commitment to social justice, it was sometimes difficult to not speak a common language. Some respondents noted that they often used jargon that identified them as educational elites, which created additional challenges: "[School] helped me by giving me knowledge, but educational privilege has been a tough thing for me to manage.” Another respondent added, "Leaving [college], I sort of assumed that everyone would have this knowledge [of how experiences and identities play into people’s lives].”

Interestingly, we found that this was particularly acute for students who transitioned from college into graduate programs. Our sense is that graduates who entered the workforce, although frustrated in many cases, were more positive about their experiences and their ability to apply the values they learned through the minor to their work, whereas 
those in MSW programs expressed more frustration about their fellow students not possessing the same level of insight into social issues.

I find that my colleagues [in the MSW program] don't have the in-depth understanding of social inequalities/issues that I... have, and this can be quite frustrating.

I've been struggling with being frustrated with my peers because of their lack of inclusivity or multicultural awareness....My classmates often come to me with questions in these areas because of my experiences in [the minor].

\section{Stress of Working in Non-Profit Organizations}

A third emergent theme in the findings was the level of stress and frustration faced by respondents as they transitioned from the university to work in non-profit and communitybased environments. Like many millennial students, the transition from college to the workforce was the first time that these young adults had held full-time positions in the nonprofit sector, although some had worked in part-time or volunteer positions while in school. Their exposure to non-profit and community-based organizations, through service learning courses, internships, field experiences, and other volunteer activities, tended to be bounded, time-limited, and in some cases engineered specifically for student learning and thus did not accurately expose students to the realities of working full-time in the field.

Non-profits, particularly smaller, service-oriented organizations, face unique challenges and limitations that are not often discussed in the college classroom, leading some students to have unrealistic expectations of what work in this environment would entail. Though they were committed to and excited about working in organizations devoted to social change, our respondents did not always have a sense of what this work would be like on a day-to-day basis.

As one respondent noted, "Working for a non-profit can be extremely frustrating due to lack of funding and organization." This was echoed by another who said, "Understanding agency limitations has been the most challenging." Several also expressed feelings of disillusionment with their job duties, which were not always as explicitly related to community change as they would have hoped. One respondent commented:

The biggest challenge for me is just the days when I go into work and I'm doing the most seemingly unrelated, random task. And I should say it's not the type of task like getting coffee, but more like writing a random report for something that doesn't really change the way programs are going to run.

[Social justice work] is easier to be passionate about when you're talking about [it] in class, but much harder when it's your 40+ hours a week job. It's filled with mundane tasks that seem totally unrelated to the mission...You have to have something that ignites that spark.

While these respondents were not about to give up on community change work, they did wish that they had been more prepared for the day-to-day work of non-profit employees, 
particularly in the first few years after graduation when their jobs are likely to be entrylevel positions that lack major decision-making responsibility.

These basic challenges of operating in a non-profit organizational culture were compounded for some by the stress of trying to balance their passion for social-justiceoriented work with a reasonable level of self-care. One recent graduate noted, "I think the biggest challenge so far is money...I am making barely enough to live on.” Others focused less on financial concerns than on fears of losing their passion for change work as a result of financial, physical, or emotional stress. One respondent described her biggest challenge as "being treated like just because I have a heart and care about the issues, I will do anything and everything to get it done, including getting pushed to the point of physical and mental exhaustion." "One of my main challenges," another respondent said, "is separating my career from my personal life. I want so much for my clients to succeed in their goals but I have to realize that at the end of the day, I can only do what I can do.”

\section{Overwhelming Sense of "Real World" Injustices}

A fourth emergent theme from the survey involved efforts to grapple with the overwhelming nature of social injustices and oppression in the "real world." While some students come to college with a strong understanding of the realities of injustice, other students-especially those from more privileged backgrounds-lack a realistic picture of the challenges faced by many individuals and communities. While short-term projects, service learning courses, and internship experiences in and with communities can open students' eyes to issues they did not know existed, they cannot fully prepare them for what it is like to live these experiences on a regular basis. This is especially true for students in nonsocial-work degree-granting programs who do not have the same expectations for sustained field placements as most BSW and MSW programs.

One respondent noted, for example, that her biggest challenge is "just dealing with the personal stories from clients," while another said that she has been surprised by how challenging "working with clients from different backgrounds can be." For both of these respondents, as well as many others, learning about the very different - and often unjust life experiences of clients has been enlightening but also disheartening. While some described finding ways to cope with issues of injustice, others mentioned the "immensity" of social problems and of the work they saw before them:

I have faced burn-out and a type of exhaustion from the utter "brokenness" of the world...But I also get to see the other side of it. I have been able to rally with a team doing extraordinary work and focus on that rather than the things that we aren't/can't be doing.

[I have been] overwhelmed by the immensity of social issues that still exist in the world, let alone our society. It is difficult to grasp the fact that I cannot positively impact every issue I come across.

Recognizing "real world" injustices has also challenged alumni to draw on the relationship-building skills they developed in courses and service experiences while in school. As they described it in response to our survey questions, this has involved not only 
becoming aware of the very real problems and injustices communities face but also of the uniqueness of each community's experiences and therefore of the steps it will take to bring about change. Acknowledging diversity and building relationships across difference were things the students learned about in the classroom but still struggled with as they entered work in the field. As one respondent said, "I learned in [classes] that you must always come into a community understanding that it is different but what I was not ready for was how different." Overall, while our respondents repeatedly described the ways that their social justice courses and other activities had helped them to deal with the challenges they faced as they moved into social-justice-oriented jobs post-graduation, they still encountered some challenges for which they felt unprepared.

\section{Implications for Social Work Practice and Research}

The findings from our research suggest that there are many challenges that students face as they transition into post-college civic engagement and social justice work experiences. Given that many students first work in non-profit settings and that these first post-college jobs often set the course for students' desire to remain in social work or other social justice-oriented careers, it is critical that social work as a field pays particular attention to understanding transitions. Similarly, it is important that social work agencies and community-based organizations be able to understand the mindset and transitional issues facing the graduates that become their newest employees or serve as long-term interns through programs like AmeriCorps or City Year. Understanding these challenges could potentially lead to easier transitions and higher job satisfaction by recent graduates and less turnover and workplace frustration by non-profit and social work agencies.

While it is no surprise that students face challenges when they leave the university setting and enter the "real world," there have been very few studies that attempt to capture the perspectives of recent graduates and to name and understand the nuances of these challenges. One of our respondents described this transition as moving beyond the "social justice bubble" that exists in many campus-based settings. While we may recognize that this bubble exists, as educators and researchers we often have not put much effort into understanding or preparing students for what leaving it will entail. In this next section we explore potential strategies for supporting transitions and discuss suggestions for future research.

\section{Strategies for Social Work Schools to Support Transitions}

Because of the investment of social work schools in supporting social justice and social work agencies, social work educators play a special role in helping to develop strategies for successful transitions. While some social work schools already offer social justice minors as a form of connection to undergraduates, others schools, especially those without BSW programs, may look to opportunities to offer course work for undergraduates in order to provide more realistic understanding of work in social justice organizations.

For example, social work schools might strengthen opportunities to connect undergraduate students to the daily realities of work in the social justice realm while they are still in school. While MSW and BSW programs are required to provide field 
experiences that enable longer exposure to community organizations, social justice minors or programs are not; therefore, exposure to the actual day-to-day realities of work may not occur. Such exposure might be accomplished, however, by developing a capstone or seminar to explicitly discuss the transition from student to graduate and/or by providing opportunities for students to learn about the day-to-day workload of non-profit employees, graduate students, and social justice advocates, particularly those in their first one to three years out of college.

Another strategy would be to include more opportunities for students to engage in conversations with recent graduates about their daily work life. Courses could be developed that focus on the reality of social change work to expose students to an understanding of what is expected of them (i.e., to provide a realistic picture of what such work is like), what the tensions and issues are in the daily tasks of social justice work, the logistics of working in a non-profit, such as sample schedules, work pacing, and need for flexibility-and the impact of the work on the employees, including accomplishments and growth.

In addition to providing more concrete examples of what social justice work is like in the "real world," courses and co-curricular programs in social work and other related fields also need to help students to develop the specific skills they are likely to need for their post-graduation lives and work. Based on the challenges described by our survey respondents, we argue that the following types of skills should be prioritized: relationship building, critical reflection and perspective-taking, cultural and educational humility, and self-care.

The types of relationship building we have in mind include not only establishing relationships with people in one's new community in order to learn from their perspective but also intentionally seeking out relationships with those who can inspire and support one in the face of challenges. Both require similar skills in networking and communication with diverse community members, but the former involves using these skills to meet and interact with like-minded and non-like-minded people with an eye toward building coalitions across difference, while the latter entails maintaining contacts with people outside of one's new community as well as developing relationships within that community with people who share one's commitment to social justice.

Our respondents' comments about "educational privilege" and the isolation they experienced as a result of this tie directly to the recent call in social work education for the development of "cultural humility" (Ortega \& Faller, 2011). This is a practice that deemphasizes the role of the practitioner as an expert in cultural and diversity frameworks and focuses on being open to learning about people through their own perspectives and lived experiences as a core component of practice (Ortega \& Faller, 2011), as well as on the need for frank discussions about the role of privilege and social identity within social change work. Critically important to student transitions is the ability for students to be aware of and cognizant about their own privilege. In this minor, for example, with a population that is largely white, possesses an upper socioeconomic status (SES), and comes from an elite public university, privilege emerges from student's educational perspectives, racial and ethnic identity, and SES, among other social identities. Open and honest discussions about how to recognize one's own privilege and the implications for practice 
are very important. These discussions occur in the classroom on a regular basis, covering topics such as "privilege," "entering communities," "fighting white savior complexes," and "critiquing the concept of "help"” among others. They also happen outside of the classroom in minor-sponsored workshops, retreats, and network discussion activities. Most recently, the minor developed a social justice retreat aimed at grappling with critical questions around privilege and social change. As students are able to be more open and humble in their engagement, they may be able to engage more deeply with others, even those of differing perspectives and persuasions and find a common humanity to listen and learn, even if they disagree.

\section{Strategies for Administrators of Social Justice and Civic Engagement Organizations}

While social work schools have the potential for the biggest influence on students before they graduate and take entry-level social justice positions, the non-profits and social work agencies that hire the students as employees or volunteers can also incorporate strategies to support this transition. Based on our respondents' descriptions of the struggles they experienced during their transition out of college, non-profits - especially those that recruit new employees from a wide geographic region - may need to do more to equip new employees to build relationships in new and different settings. Non-profit agencies like those that participate in multi-year service programs such as AmeriCorps and City Year should consider orientations as opportunities for relationship and network building among students and for connecting students to the broader community. While orientations often occur, organizations should reflect on the ways their orientations can be more intentional in helping new graduates enter the community and build the connections that may ease some of the initial tensions.

Additionally, administrators of social justice organizations may want to seek opportunities to help new social-justice-focused graduates get involved in their work. While many of our respondents were involved in a social-justice-focused experience after graduation, we know that some are seeking additional opportunities to get involved or are seeking meaningful volunteer experiences to enhance their day-to-day work. One suggestion is for non-profit organizations to create more partnerships with local companies and agencies to encourage service days. In this way, organizations can make connections to those graduates who are social-justice-focused but engaged in other occupations or are seeking additional opportunities to be involved in social justice work. Given the challenges our respondents expressed of finding others who are social-justice-oriented in their new communities, administrators may also seek alternative forms of service days or voluntary service groups that promote engagement and help build networks of social-justice-minded young professionals.

Although critical reflection is often a regular part of student experiences during college, it is less often practiced in busy non-profits. Our alumni survey reminded us that students need to not only participate in facilitated reflection during their time in school but also to develop their own tools for continuing this type of reflection as they move into the world of social justice work. Some of this may be individual work, such as encouraging new graduates to create interactive blogs to support self-reflection and shared learning or to participate in online forums to enable graduates to reflect on and share their experiences 
related to common issues. Some might also be organizational work, such as encouraging new employees to create portfolios to capture their experiences, providing weekly learning and reflection opportunities, and creating settings in which to share reflections and learning in broader organizational contexts like newsletters, websites, and conferences.

One place for critical reflection to occur is within supervision sessions. Rethinking what supervision looks like and how supervision is provided may be necessary. Depending on an organization's structure, supervision may need to happen more often or may need to focus on reflection of skills and experiences gained in the process. Supervision may occur one-on-one, in small groups, or even through ongoing communication using social media. Regardless of process, it is important to remember that supervision and points of connection between new employees and senior leadership help shape expectations, process experiences, and also help new employees see the long-term horizon of working in social justice organizations. In other words, supervision can be not only a space to deal with immediate issues but also an opportunity for learning context and history and for putting the immediate issues into perspective.

Self-care also emerged as an important theme in our survey. Understanding what selfcare is and why it is valuable on an intellectual level, however, does not mean that one knows how to practice it, particularly during a time of transition as one adjusts to the demands of a new job or living situation. Social justice non-profits and agencies are perfectly positioned for helping students learn about and begin to practice such strategies. For example, non-profits might partner with social work schools to offer mini-courses, workshops, and co-curricular activities focused on realistic stressors and self-care strategies practiced in the field. The college years represent a significant time for students to prepare themselves for the stresses they may face after graduation; if they have begun these habits in a more secure and comfortable setting, it will be easier to carry them over to a new setting rather than attempting to develop new strategies in the midst of the transition.

\section{Strategies for Supporting Alumni}

While all of the strategies mentioned here have the potential to significantly impact students' transitions, it is also critically important, based on our respondents' comments, that social work and other social-justice-oriented programs consider strategies for longerterm, continuous support of their alums, and, in particular, a focus on keeping alumni connected after graduation. While many schools of social work and academic programs try to maintain connections with alumni, we would push efforts to move beyond calling on alumni as donors and rather re-think alumni efforts to provide ongoing support for graduates in their work worlds and in furthering their commitments to social justice. This concept of moving from alumni as donors to a more active recognition of alumni engagement is being modeled nationally through programs like Citizen Alum, a national initiative of multiple colleges and universities aimed at moving from "donors to do-ers" and to "building multigenerational communities of active citizenship and active learning" (Citizen Alum as cited in Ellison, 2013, p. 3). 
Other practical ideas for alumni engagement include creating alumni networks focused on social justice, linking alumni by geographic location or issue of interest to support collaborations and reduce isolation, providing resources and training to support ongoing reflection and strategies for self-care, and linking recent alumni to others with longer-term positions and engagement in social justice work through a post-graduate mentorship program.

In our own program, we are experimenting with a variety of ways to engage alumni in additional training through on-site sessions and web-based seminars on topics and strategies related to social justice work in the "real world." We are also working to develop hubs of graduates across geographic areas (e.g., major metropolitan hubs and regional areas) as well as linking students across shared experiences (e.g., graduate students, Teach for America, AmeriCorps, City Year, community organizers, program developers, etc.) for reflection, connection, and support. Lastly, we are actively working on opportunities to link alumni to graduating seniors to share and reflect on their experiences as an additional way of preparing those seniors for their transition into the world of social justice work.

An additional recommendation would be to explore the potential for addressing the economic realities of social justice work and the barriers that these create for recent graduates. Schools of social work should work with alumni and agencies to develop innovative solutions such as loan forgiveness, education scholarships, professional development/continuing education credits, high quality benefits, and work-life balance programs to explore additional venues for supporting and sustaining new employees in their efforts to engage in social justice work over the long haul.

\section{Limitations and Future Research}

As with any research, our study faced limitations that need to be acknowledged and accounted for in future efforts. While only a pilot, we recognize that our sample does not include the experiences of students that have returned to school as non-traditional students and therefore have had work or family experiences that will shape their transitions to postcollege life. Similarly, this research did not look at the link between prior work experience and transitions, which also would potentially impact how students experience challenges. Last, using emails as a tool for outreach was a limitation because of the number of former students who did not respond in a timely manner. We learned that our outreach emails were sometimes sent to old university emails that frequently went unchecked. Although we had a decent response rate, many other alums emailed us after the survey closed realizing that they had wanted to participate but had missed the deadline. In the future we will plan to use additional measures to ensure we have the most accurate email lists for outreach while also using other platforms such as social media to contact potential respondents.

Despite these limitations, we see this pilot as a base from which to develop future research on pathways and trajectories of students in social justice programs. In particular, longer-term follow-up of graduates is needed to learn about ways to facilitate civic engagement and social justice activities post-graduation. For example, what is the trajectory for most of these graduates at various intervals (e.g., one, three, or five years) post-graduation related to civic engagement and social justice work? What are challenges 
that continue to emerge at various intervals? How do experiences, both during school and post-graduation, shape perspectives over time?

In our research it was difficult to tease apart the experiences between those in graduate school and those in employment, but future research should look specifically at differences between transitions to graduate programs (social work or otherwise), short-term volunteer employment experiences, and longer-term employment opportunities. More research is also needed to explore the "valued added" impact of participation in social-justiceintensive programs as compared to more traditional academic programs. Is there a difference, for example, between the civic engagement and social justice trajectories of graduates from these programs and those of other graduates from their university? Additionally, it will be important for future research to explore the impact of work settings and context on alumni experiences. What are the various experiences of graduates in different types of workplace settings? In what ways do those settings differentially impact civic engagement and social justice values and trajectories, and what remains common across all settings?

Finally, further research and discussion needs to focus more closely on the infrastructure needed to truly connect schools of social work and employers around issues in the field. Too often there is a disconnect between a school's curricular preparation and the needs of employers (Polach, 2004). With rare exceptions (such as the IV-E child welfare programs), there is almost no infrastructure or research to support ongoing engagement between schools of social work, administrators of agencies and non-profits, and supporting alumni. Lacking these discussions, and research to document their findings, the social work field risks creating a mismatch for the field moving forward.

\section{Conclusion}

As a field committed to preparing future generations of social justice advocates and change agents, social work - together with allied fields - must continue to seek out practices that support the transition from undergraduate education to next steps in social justice engagement, helping graduates to cope, develop, and thrive rather than to burn out in the face of initial challenges. It is therefore critical that leaders in social work and other social-justice-oriented academic programs understand the challenges and issues students face as they graduate and move into the "real world." Only by hearing from recent graduates themselves can we gain a sense of not only the knowledge and skills our students need to develop while in school but also the support they need from their academic institutions and programs once they graduate.

This study offers a first look at what very recent graduates of a social-justice-oriented program in a school of social work have encountered upon leaving undergraduate education and moving into the world of work, service, and graduate school and, by doing so, points educators, practitioners, and researchers in social work and social-justiceoriented fields toward new strategies that will enable us to produce graduates who become life-long change agents. 


\section{References}

Alsop, R. (2008). The trophy kids grow up: How the millennial generation is shaking up the workplace. San Francisco, CA: Jossey-Bass.

Arnett, J. (2004). Emerging adulthood: The winding road from the late teens through the twenties. NY: Oxford University Press.

Besser, T. L. (2012). Inside the black box: College graduation and civic engagement. Journal of Academic Ethics, 10, 313-325. doi: http://dx.doi.org/10.1007/s10805-012$\underline{9167-2}$

Boyatzis, R. E. (1998). Transforming qualitative information: Thematic analysis and code development. Thousand Oaks: Sage.

Bringle, R., Clayton, P., Steinberg, K., \& Studer, M. (2011). Designing programs with a purpose: To promote civic engagement for life. Journal of Academic Excellence, 9(2), 149-164. doi: http://dx.doi.org/10.1007/s10805-011-9135-2

Burke, T. K. (2011). Civic professionalism: Using service learning to educate social work students as citizens. Advances in Social Work, 12(1), 21-32.

Colby, A., Ehrlich, T., Beaumont, E., \& Stephens, J. (2003). Educating citizens: Preparing America's undergraduates for lives of moral and civic responsibility. San Francisco: Jossey-Bass.

Corbin, J., \& Strauss, A. L. (2008). Basics of qualitative research ( $3^{\text {rd }}$ ed.). Thousand Oaks, CA: Sage.

Creswell, J. W. (2014). Research design: Qualitative, quantitative, and mixed methods approaches. Thousand Oaks: Sage.

Denzin, N. K., \& Lincoln, Y. S. (2011). The Sage handbook of qualitative research (4th ed.). Thousand Oaks: Sage.

Ellison, J. (2013, February). Civic engagement in the fourth dimension: The real time of real lives. Presentation at North Carolina Campus Compact Civic Institute. Retrieved May 12, 2014, from http://www.citizenalum.org/wpcontent/uploads/2013/05/Citizen-Alum-Presentation-red-March-2013.pdf

Flanagan, C., \& Levine, P. (2010). Civic engagement and the transition to adulthood. Project Muse, 20(1), 159-179. doi: http://dx.doi.org/10.1353/foc.0.0043

Glaser, B. G., \& Strauss, A. L. (1967). The discovery of grounded theory: Strategies for qualitative research. Chicago: Aldine.

Glass, C. (2013). Strengthening and deepening education for personal and social responsibility. New Directions for Higher Education, 2013(164), 83-94. doi: http://dx.doi.org/10.1002/he.20077

Glass, L. L. (2012). Civic reflection: A pedagogical teaching strategy to enhance student civic engagement. The Journal of Baccalaureate Social Work, 17, 39-52. 
Goldsberry, K. (2007). Engaged citizens: Connections between collegiate engagement and alumni civic involvement [Electronic Dissertation]. Retrieved from http://rave.ohiolink.edu/etdc/view?acc_num=ohiou1178311155

Harkavy, I. (2006). The role of universities in advancing citizenship and social justice in the $21^{\text {st }}$ century. Education, Citizenship, and Social Justice, 1(1), 5-37. doi: http://dx.doi.org/10.1177/1746197906060711

Hoy, A., Johnson, M., \& Hackett, R. (2012). Disciplining higher education for democratic community engagement. In D. W. Butin \& S. Seider (Eds.), The engaged campus: Certificates, minors, and majors as the new community engagement (pp. 177-186). New York, NY: Palgrave Macmillan.

Keen, C., \& Hall, K. (2008). Post-graduation service and civic outcomes for high financial need students of a multi-campus, co-curricular service-learning college program. Journal of College \& Character, 10(2), 1-15. doi: http://dx.doi.org/10.2202/1940-1639.1066

Mitchell, T., Battistoni, R., Keene, A., \& Reiff, J. (2013). Programs that build civic identity: A study of alumni. Diversity and Democracy, 16(3), 22-23.

Murphy, K., Blustein, D., Bohlig, A., \& Platt, M. (2010). The college-to-career transition: An exploration of emerging adulthood. Journal of Counseling and Development, 88(2), 174-181. doi: http://dx.doi.org/10.1002/j.1556-6678.2010.tb00006.x

Ortega, R. M., \& Faller, K. C. (2011). Training child welfare workers from an intersectional cultural humility perspective: A paradigm shift. Child Welfare, 90(5), 27-49.

Polach, J. (2004). Understanding the experience of college graduates during their first year of employment. Human Resource Development Quarterly, 15(1), 5-23. doi: http://dx.doi.org/10.1002/hrdq.1084

QSR International Pty Ltd. (2012). NVIVO qualitative data analysis software [Version 10].

Richards-Schuster, K., Ruffolo, M., \& Nicoll, K. L. (2015). Integrating social work into undergraduate education through a community action and social change multidisciplinary minor. Journal of Social Work Education, 51(2), 329-342.

Richards-Schuster, K., Ruffolo, M., Nicoll, K. L., Distelrath, C., \& Galura, J. (2014). Using e-portfolios to assess program goals, integrative learning and civic engagement: A case example. International Journal of ePortfolio, 4(2), 133-141.

Roksa, J., \& Arum, R. (2012). Life after college: The challenging transitions of the academically adrift cohort. Change: The Magazine of Higher Learning, 44(4), 8-14. doi: http://dx.doi.org/10.1080/00091383.2012.691857

Rome, S. H., \& Hoechstetter, S (2010). Social work and civic engagement: The political participation of professional social workers. Journal of Sociology and Social Welfare, 37(3), 107-129. 
Steinberg, K., Hatcher, J., \& Bringle, R. (2011). A north star: Civic-minded graduates. Michigan Journal of Community Service Learning, 18(1), 19-33.

Wendlandt, N., \& Rochlen, A. (2008). Addressing the college-to-work transition: Implications for university career counselors. Journal of Career Development, 35(2), 151-165. doi: http://dx.doi.org/10.1177/0894845308325646

\section{Author note}

Address correspondence: Katie Richards-Schuster, PhD, Assistant Professor, School of Social Work, University of Michigan, 3850 SSWB, 1080 S. University, Ann Arbor, MI 48109. Email: kers@umich.edu 